\title{
The laser welding technique applied to the non precious dental alloys procedure and results
}

\author{
C. Bertrand, ' Y. Le Petitcorps, ${ }^{2}$ L. Albingre, ${ }^{3}$ and V. Dupuis, ${ }^{4}$
}

\begin{abstract}
Aim The laser welding technique was chosen for its versatility in the repair of dental metal prosthesis. The aim of this research is to assess the accuracy, quality and reproducibility of this technique as applied to Ni-Cr-Mo and Cr-Co-Mo alloys often used to make prosthesis

Method The alloy's ability to weld was evaluated with a pulsed Nd-Yag Laser equipment. In order to evaluate the joining, various cast wires with different diameters were used. The efficiency of the joining was measured with tensile tests. In order to understand this difference, metallographic examinations and $\mathrm{X}$ Ray microprobe analysis were performed through the welded area and compared with the cast part.

Results It was found that a very slight change in the chemistry of the $\mathrm{Ni}-\mathrm{Cr}$ alloys had a strong influence on the quality of the joining. The Co-Cr alloy presented an excellent weldability. A very important change in the microstructure due to the effect of the laser was pointed out in the welding zone, increasing its micro-hardness.

Conclusion The higher level of carbon and boron in one of the two $\mathrm{Ni}-\mathrm{Cr}$ was found to be responsible for its poor welding ability. However for the others, the maximum depth of welding was found to be around $2 \mathrm{~mm}$ which is one of the usual thicknesses of the components which have to be repaired.
\end{abstract}

Since 1990, pulsed Nd-Yag dental lasers have been commercially Sused in Europe. Manufacturers present the laser welding technique as a new, rapid, economic and accurate way for joining metal. In prosthetic dentistry, this technique has the following advantages:

- The laser device saves time in a commercial laboratory because all welding is done directly on the master cast. Inaccuracies in assembly caused by transfers from the master cast along with investment and heat distortions are reduced. ${ }^{1,2,3,4}$

- It is consistently possible to weld very close to acrylic resin or ceramic parts with no physical (cracking) or colour damage. ${ }^{5}$

- Potentially, all metals can be joined but particularly titanium alloys. ${ }^{6,7,8,9,10,11}$

- Laser welding joints have a high reproducible strength for all metals, consistent with that of the substrate alloy. ${ }^{12,13,14}$

Considering all these advantages, all dental technician should

\footnotetext{
${ }^{1 *}$ Doctor, Dental School, Laboratoire Odontologique de Recherche, 16 à 20 Cours de la Marne, 33800 Bordeaux Cedex France ${ }^{2}$ Professor in Biomaterials and Chemistry, ${ }^{3}$ Ingineer, ICMCB-CNRS, 87, Avenue du docteur A. Schweitzer, 33608 Pessac France 4 Professor, Dental School, Laboratoire Odontologique de Recherche, 16 à 20 Cours de la Marne, 33800 Bordeaux Cedex France

${ }^{*}$ Correspondence to: C. BERTRAND, rue de la Mane, 33490 Saint Pierre d'Aurillac-France

E-mail:caro.bertrand2@wanadoo.fr

REFEREED PAPER

Received 22.02.00; Accepted 09.11.00

(C) British Dental Journal 2001; 190: 255-257
}

have a laser in their laboratory. However, looking at the available literature, since 1970 many experiments have been conducted into non precious and precious alloys and have shown contradictory results, probably because the experimental procedures used were different. ${ }^{15,16,17,18,19}$ Therefore no comparison could be made. In this study, the weldability of three non precious alloys was investigated. The procedure consisted of determining the appropriate welding parameters which could achieve a deep joining in depth without cracks or gas entrapments in the welding area. The quality of the joining was checked by metallographic observations on polished sections. Wires of different diameters were then laser-welded and tested in tension. In order to understand the different behaviours between the three alloys ( $2 \mathrm{Ni}-\mathrm{Cr}$ and $1 \mathrm{Co}-\mathrm{Cr}$ based alloys), the composition of the welded area was determined by a X-Ray microprobe. Particular attention was given to the role played by the impurities.

\section{Methods}

Chemical compositions

Two Ni-Cr-Mo alloys and 1 Co-Cr-Mo alloy, manufactured by Dentaurum (Pforzheim, Germany) were chosen for their applications in the dental field (Table 1):

$1 \mathrm{G}$ mou is a low cost alloy used for crowns and bridges.

2 Remanium Cs is used for ceramic fixed partial dentures.

3 GM 800 is a cobalt chrominium alloy used for removable and fixed partial dentures

Table I Chemical composition of the three alloys (Data from Dentaurum of as-casted materials).

\begin{tabular}{lcccccr}
\hline Alloy & $\begin{array}{c}\mathbf{N i} \\
(\mathbf{W t} \%)\end{array}$ & $\begin{array}{c}\mathbf{C o} \\
(\mathbf{W t} \%)\end{array}$ & $\begin{array}{c}\mathbf{C r} \\
(\mathbf{W t} \%)\end{array}$ & $\begin{array}{c}\text { Mo } \\
(\mathbf{W t} \%)\end{array}$ & $\begin{array}{c}\text { Si } \\
(\mathbf{W t} \%)\end{array}$ & $\begin{array}{r}\text { Others } \\
(\mathbf{W t} \%)\end{array}$ \\
G-Mou & 67 & - & 26 & 5 & $\mathrm{I} .5$ & $\mathrm{C}, \mathrm{B}, \mathrm{Mn}<\mathrm{I}$ \\
RemaniumCs & $6 \mathrm{I}$ & - & 26 & $1 \mathrm{I}$ & $\mathrm{I} .5$ & $\mathrm{Fe}, \mathrm{Ce}, \mathrm{Al}<\mathrm{I}$ \\
GM-800 & - & 64.5 & 30 & 5 & - & $\mathrm{C}: 0.3 \mathrm{Mn}: 0.2$ \\
\hline
\end{tabular}

Laser parameters and welding conditions

In order to determine the welding conditions against the metal thickness and the ability of the laser device, two series of cast wires (0.6 to $2 \mathrm{~mm}$ thick), and five specimen DIN 50125 (3mm thick) were prepared by investment casting. The samples were then cut, joined by hand, edge to edge and welded without fillers or fluxes, using a commercial Nd-Yag laser (DL 2002 manufactured by Dentaurum) whose technical characteristics are given in table 2. In order to avoid the laser beam reflection and to improve the weld penetration, all the wires were sand-blasted with alumina powders and welded under Argon shielding atmosphere to decrease the oxidation contamination.

All the samples were welded using the same procedure. The Laser conditions depend on the thickness and the volume of material to be welded (Table 2).

Each wire was first assembled by the 4-cardinal points and then 


\section{RESEARCH prosthodontics}

Table 2 The Main parameters which were determined to weld the 2 NiCrMo alloys with the DL2002

\begin{tabular}{ccc}
\hline Thickness MM & Tension $\mathrm{V}$ & Pulse MS \\
0.6 & 255 & 3 \\
0.8 & 255 & 4 \\
1 & 260 & 5 \\
1.2 & 270 & 6.5 \\
1.5 & 275 & 9.5 \\
2 & 285 & 10.5 \\
3 & 295 & 13.5 \\
\hline
\end{tabular}

Nd-Yag laser. Power of this laser: 20 watts, beam size : $0,2 \mathrm{~mm}$, exposure duration is given in table 2 with a frequency $=\mathrm{lhz}$

fully welded all over the circumference point per point, with a $80 \%$ overlapped by the next point to avoid distortion.

\section{Microstructure, chemical composition and mechanical properties}

The wires were tested in tension using an INSTRON type machine with a cross-head speed of $0.5 \mathrm{~mm} / \mathrm{min}$. They were then compared to the as-cast material in order to evaluate the quality of the welding. The stress-strain curves were used to determine the ultimate tensile strength and the yielding elongation in order to follow the embrittlement caused by the welding zone.

The welded area was cut in each wire axis perpendicular to it. They were then embedded in an epoxy resin, polished, chemically etched with an appropriate solution and observed with an optical microscope. Additionally, the micro-hardness (Vickers type) was measured both in the welded and the heat affected zone (HAZ) and then compared to the cast alloy.

The chemical composition was measured by a conventional X-ray microprobe. Energy Dispersive Spectroscopy (EDS) analysis was performed to assess the local element variations caused by an eventual segregation phenomena during the process of rapid solidification.

\section{Results}

Whereas the two Ni-Cr alloys have a very similar chemical composition, their weldability is very different (Figure 1):

- G mou All wires, apart from the $0.8 \mathrm{~mm}$ one, broke in the weld, and the tensile strength decreased as the wire diameter increased.

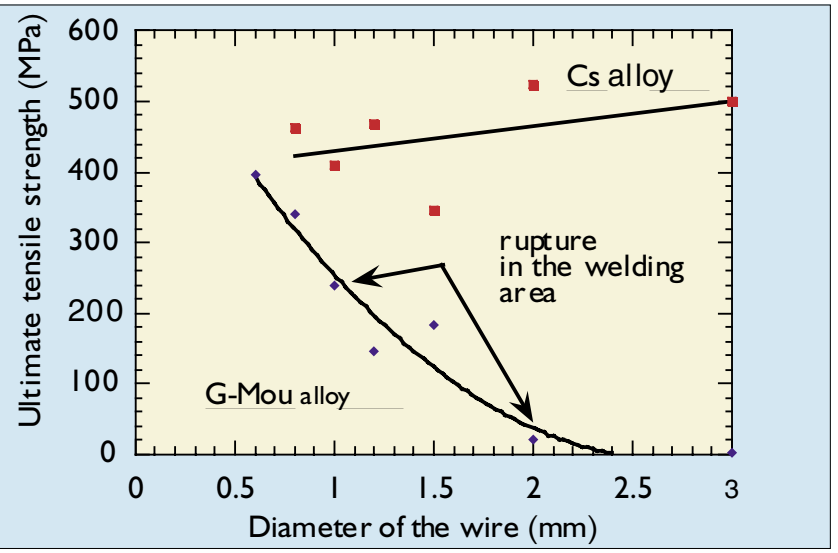

Fig. I Tensile strength versus the diameter measured at room temperature.

The welded area became increasingly brittle. The analysis under an optical microscope showed that the proportion of the welded area compared with the non welded area (in the centre of the wire) decreased with the diameter of the wire. The welding penetration was not deeper than $0.5 \mathrm{~mm}$ for all specimens. The microstructure of the welded zone appeared very fine as a result of the very rapid process of solidification whereas the cast metal showed a dendritic microstructure due to a slow cooling process.
Perpendicular cracks to the wire axis were present in all wires starting from the non-welded area with a large opening width. In order to determine if the cracks were due to the misalignment of the two pieces during the welding stage or due to residual stresses induced by the change of the microstructure, a laser shot was applied to the surface of the cast metal. This area also presented some cracks and it is now clear that the modification of the microstructure due to the rapid heating and solidification process can be a real problem and affect the quality of the repaired component.

- Remanium CS There was no straight correlation between the tensile strength values and the diameter of each wire. The breaking usually appeared in the cast metal except for the $3 \mathrm{~mm}$ specimen which broke in the welded area. The variations in the tensile strength values are the result of:

(1) the difficulty of aligning the two pieces during the welding process for the wires of the smaller diameters,

(2) the differences in the microstructures due to the speed of solidification depending on the amount of metal which solidifies (small grains for small diameters of wires, larger grains when the diameter increases).

Whatever the diameter used, the alloy showed a ductile behaviour. Some representative curves of welded and non welded samples are illustrated on figure 2. The microstructure observed in the welding area looked like the previous one, but for all the diameters used, the wires were completely welded. The initiation and propagation of the cracks were also different. A microcracking appeared, arising from a defect (micro-porosity) and propagated along the grain boundaries in the direction of the heat affected zone (HAZ), (Figure 3), whereas with the previous alloy, the rupture was controlled by the non-welded zone in the centre of the wire. This difference in cracks propagation can partly explain the differences in the tensile strength results between the two alloys.

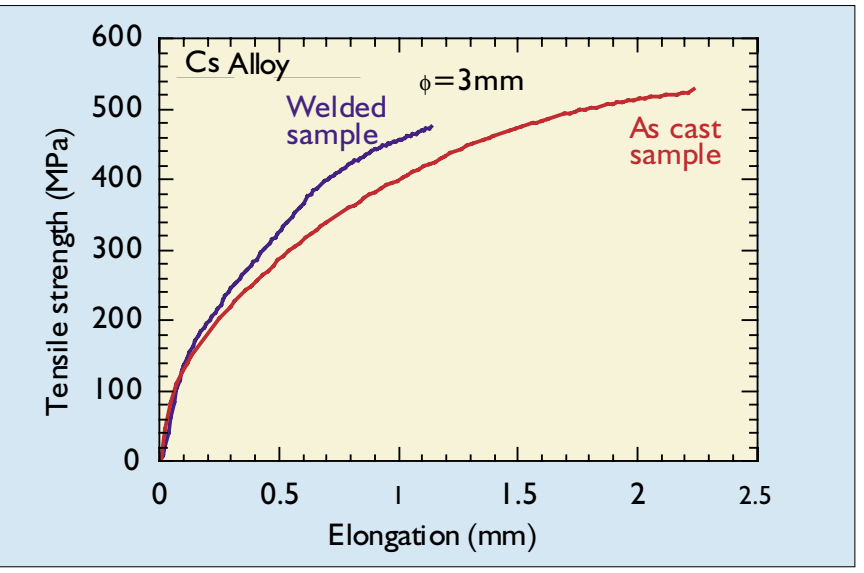

Fig. 2 Stress-strain curves plotted for the Cs alloy. Only one curve is shown because the others were similar

- GM 800 The results showed that the fracture appeared in the welding areas up to the $1.5 \mathrm{~mm}$ diameter. The disparity in the results with the $3 \mathrm{~mm}$ specimen proves that there is a real difficulty to repair bigger samples, probably due to the alignment of the wires during the welding stage. Indeed, the technician had to put one part of the wire close to the other and hold them firmly together in his hands. The weld using Co-Cr alloy has got a complete penetration and its microstructure looked like the Remanium Cs ones.

The determination of the microhardness showed that the central part of the weld had a higher hardness than the cast metal (Table 3). According to Roggensach, ${ }^{20}$ this is probably 


\section{RESEARCH prosthodontics}

due to the refining in the grain size and the sub-structure which appears during the rapid solidification stage.

Table 3 Microhardness values for the NiCrMo alloys

\begin{tabular}{lcc}
\hline $\begin{array}{l}\text { Vickers microhardness: } \\
\text { HVO, I }\end{array}$ & Gmou & Rémanium Cs \\
Cast alloy & $245+/-25$ & $220+/-20$ \\
Central part of the weld & $330+/-30$ & $340+/-35$ \\
\hline
\end{tabular}

10 measurements, 5 measurements per sample and 3 samples

\section{Discussion and conclusion}

In this study, a small change in the chemical composition of the Nibased alloys caused a very important difference in the weldability. Particular attention was given to the difference in the chemical composition of the welded areas and compared with the original alloy composition.

In the parent metal, the main constituents nickel and chromium were both present in the dendritic zone. Mo and Si were associated in the interdendritic area, probably as an intermetallic compound.

In the welded area, the composition changes were fairly small. A slight evaporation of chromium was observed, Mo and Si were still together but rejected at the grain boundaries and along the cracks.

Regarding the $\mathrm{G}$ mou alloy, some boron was also rejected along the cracks as well as the Mo and Si atoms. Many authors have reported that intentional minor alloying elements addition such as boron and carbon ${ }^{21,22,23,24}$ could affect the weldability of the nickel based superalloys. It may sometimes be necessary to make some chemical modification to improve laser weldability of some non precious alloys. Two alloys with a similar composition may react differently to the welding process and consequently the traceability of the different alloys employed in dentistry is important.

The microstructure in the welded area is granular (about $300 \mu \mathrm{m}$ for the mean grain size) and inside which there is a very fine cellular substructure with the same composition as in the initial alloy (Figure 3).

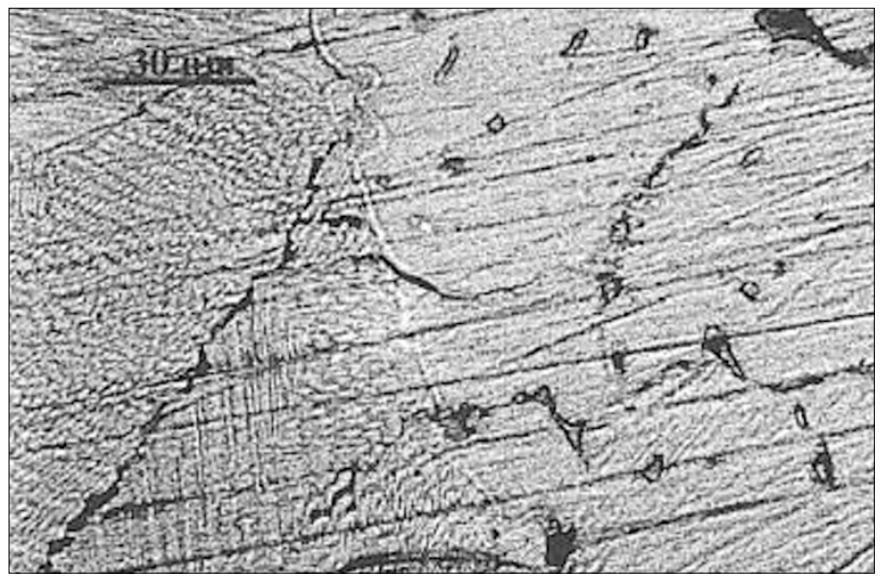

Fig. 3 Interface between welded area ( left) and the cast alloy (Cs) showing the fine microstructure and the crack propagation along the grain boundary in the welded area.

Hence, there is a very strong cohesion within the sub-structure and a weakening at the grain boundaries. These micro-structural changes could not be avoided, due to the very rapid cooling process after laser welding, ${ }^{25}$ and could not be restored with an adequate thermal treatment. Indeed, trials done at a temperature close to the melting point failed. Microcracks cannot be eliminated in the vicinity of the grain boundaries. The welded metal is affected by shrinkage during the cooling process and Matsuda ${ }^{26}$ has shown that the trend in crack initiation is affected by whether or not the base metal is restrained: the total crack length is smaller in a non-restrained condition than in a restrained condition.

This study has shown how chemical composition of the alloy can be important. The traceability seems to be indispensable and it may be necessary to adapt the alloy to allow laser welding.

The technician will be able to carry out many prosthesis repairs but he/she must accept microstructural changes caused by the rapid solidification stage. Taking account of the data presented here, it would therefore be advisable to work with fillers to compensate the difficulties of alignment during assembly of wires. Also, the chemical composition of the welded area will sometimes be different from the rest of the component. Before using this technique to repair prosthetic components, more research is required such as the influence of the cracking and/or the change in microstructure and composition on the localised corrosion behaviour in the vicinity of the welded zone.

1 Fusayama T, Wakumoto S, Hosoda H. Accuracy of fixed partial dentures made by various soldering techniques and one-piece casting. J Prosth Dent 1964;14:334-342.

2 Apotheker H, Nishimura I, Seerattan C. Laser welded vs soldered non precious alloy dental bridges: A comparative study. Lasers in surgery and medicine 1984;4:207-213.

3 Berg E, Wagnere W C, Davik G, Dootz E R. Mechanical properties of laser welded cast and wrought titanium. J Prosth Dent 1995; 74:250-257.

4 Van Benthem H. Advantages of laser welding compared to conventional joining. Quintessenz Der Zahntechnick 17:1178-1193.

5 Bertrand C. La soudure au laser : une technique d'avenir au laboratoire de prothèse. Arts et Technique Dentaires, 1995;6:363-368.

6 Shinoda T, Matsunaga Shinara M. Laser welding of titanium. Welding international 1991;5:346-351.

7 Borgstedt T. New technology for preparation of titanium crowns and bridges. Dental Labor 1991;39: 1205-10.

8 Frolov V A et al. Light beam welding thin sheets of titanium alloy.Welding International 1994;8:41-42.

9 Sjogren G, Anderson M, Bergman M. Laser welding of titanium in dentistry. Acta Odontol Scand 1988; 46:247-253.

10 Walter M, Reppel P D, Bonning K, Freesmayer W B. Six year follow-up of titanium and high-gold porcelain-fused-to-metal fixed partial dentures. $J$ Oral Rehabil 1999; 26:91-96.

11 Wang R R, Chang C T. Thermal modeling of laser welding for titanium dental restorations. J Prosth Dent 1998; 79: 335-341.

12 Dobberstein H. Orlick H. Zuhrt R. The welding of cobalt-chromium, nickel-chromium and silver-palladium alloys using a solid state laser.Zahn Mund, Und Kieferheilkunde Mit Zentralblatt 1990; 78:259-61.

13 Hoffman J. Dental laser welding technique. Procedural report.1. Quality, expense, and risks of innovative bonding technique. Dental labor 1992; 40 :1221-4.

14 Hoffmann J. Dental laser welding technique. Procedural report 2. Indications for use of innovative technique. Dental Labor 40:1321-28.

15 Gordon J R, Smith D. Laser welding of dental prosthesis: preliminary reports. J Prosth Dent 1970; 24:472-476.

16 Gordon T E, Smith D L. A laser in the dental lab. Laser Focus Magazine 1970: June :37-39.

17 Adrian J C, Huguet E F. Laser welding of a Nickel-chrome dental alloy.Milit Med, 1977;142;299-301.

18 Dobberstein H, Orlick H, Fisher P, Zhurt R. Experimental studies of the laser welding of Cr-Co alloys using a pulse laser Nd-Yag. Zahn, Mund, Und Kieferheilkunde Mit Zentralblatt 1989;77:578-579.

19 Adrian J C, Huguet E F. Laser welding of a Nickel-chrome dental alloy. Milit. Med 1977; 142:299-301.

20 Roggensach M, Walter M H, Böning K W. Studies on laser plasma welded titanium. Dent Mater 1993; 9: 104-107.

21 David S A, Jemian W A et al. Welding and weldability of Nickel-Iron alumides. Welding Journal 1985; January:22s-28s.

22 Santella M L, David S A. A study of heat-affected zone cracking in FeContaining Ni3Al Alloys. Welding Journal 1986; May:129s-135s.

23 Brooks J A, Krenzer W. Progress toward a more weldable A-286. Welding Journal June 1974; June:242s-245s.

24 Brooks J A. Effect of alloy modifications on HAZ Cracking of A286 stainless Steel. Welding Journal 1974; November:517s-523s.

25 Cieslak M J, Stephens J J, Carr J J. A study of weldability and weld related microstructure of Cabot alloy 214. Metallurgical Transactions A 1988; 19A:657-67.

26 Matsuda S, Veyama T. Solidification crack susceptibility of laser weld metal in $0.2 \mathrm{C}-\mathrm{Ni}$-Cr-Co steels : effects of bead configuration and $\mathrm{S}$ and $\mathrm{P}$ contents. Welding International 1993; 7:686-92. 